\title{
CSF and plasma levels of pro-opiomelanocortin-related peptides in reversible ischaemic attacks and strokes
}

\author{
G NAPPI, F FACCHINETTI, ${ }^{*}$ G BONO, $\dagger$ F PETRAGLIA, ${ }^{*}$ E SINFORIANI, $\dagger$ \\ AR GENAZZANI*
}

From the Department of Neurology, University of Pavia, $\dagger$ and the Department of Obstetrics and Gynaecology, University of Modena, * Italy

SUMMARY Plasma and CSF $\beta$-endorphin $(\beta$-EP), $\beta$-lipotropin $(\beta$-LPH) and ACTH levels were studied in a group of 25 patients who underwent reversible ischaemic attacks or completed strokes. CSF $\beta$-EP and $\beta$-LPH in ischaemic patients were higher than those of the control population, independently of both clinical reversibility of the cerebral damage, and the time lapse sampling and the acute event. The presence of a CT demonstrable lesion was related to the highest CSF $\beta$-EP levels. These data confirm an involvement of central opioid substances in the phenomena related to brain ischaemia. ACTH levels in the CSF did not differ from the controls; this finding further supports the concept of an independent central secretion of the different pro-opiomelanocortin-related peptides. The peripheral plasma concentrations of $\beta$-EP, $\beta$-LPH and $\mathrm{ACTH}$, were, in contrast, within the normal range, confirming that CSF and plasma contents of pro-opiomelanocortin-related peptides are differently controlled and originate from different sources.

Endogenous opioid peptides, namely those of the pro-opiomelanocortin family, such as $\beta$-endorphin $(\beta$-EP), exert a large number of biological effects which are mainly mediated by CNS receptors. ${ }^{1}$ The role of these peptides in modulating nociceptive/ adaptive responses is well known; in addition, it has recently been suggested that the opioid systems are involved in the exacerbation and reversal of focal neurological deficits of ischaemic origin in experimental models. ${ }^{23}$ Moreover, these properties of opioid ligands seem to occur independently of their role in the control mechanisms of cardiovascular functions. ${ }^{4}$

As is known from the early studies during the 70 s, focal ischaemia is accompanied by increased CSF content of neurotransmitters, mainly 5-hydroxytryptamine (5-HT) and norepinephrine. ${ }^{5}$ These changes have been attributed to an extensive and acute neuronal depletion since neither synthesis inhibition nor degradation blockade can avoid the

Address for reprint requests: Prof G Nappi, Clinica Neurolgica dell'Università, Via Palestro 3, 27100 Pavia, Italy.

Received 22 May 1984 and in revised form 7 January 1985. Accepted 17 May 1985 neurotransmitter depletion due to ischaemia. ${ }^{6}$

In vivo measurements of CSF $\beta$-EP and leucineenkephalin in a patient with focal brain ischaemia revealed double the normal concentration of the former peptide, although leucine-enkephalin levels were unchanged.' Analogous findings were obtained by the same authors in the ischaemic hemisphere of gerbils submitted to unilateral carotid ligation, whose neurological deficits were reversed by high doses of naloxone. ${ }^{8}$ Reports of studies are'contradictory about the efficacy of naloxone administration in patients with ischaemic stroke, probably owing to different selection of patients, different times of administration and different doses used by various investigators. ${ }^{9}$

As a further contribution to this topic the present study reports the results of plasma and CSF measurements of $\beta$-EP and the other proopiomelanocortin-related peptides, $\beta$-lipotropin $(\beta-\mathrm{LPH})$ and $\mathrm{ACTH}$, in a group of patients who underwent reversible ischaemic attacks, and completed strokes. ${ }^{10}$

\section{Subjects and methods}

Twenty-five patients, 21 males and four females, aged 
Table 1 Population characteristics

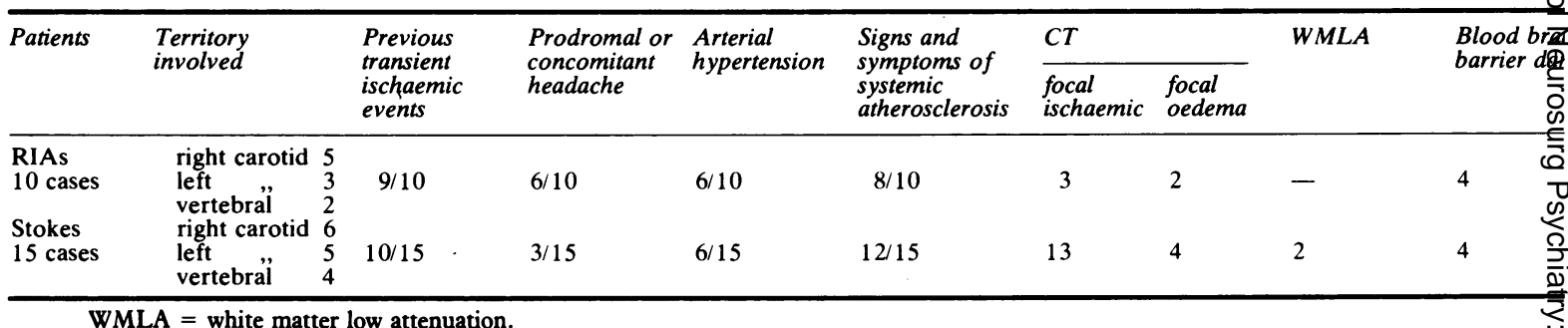

WMLA $=$ white matter low attenuation.

33-79 yr (mean $57 \cdot 76 \pm 12$ ) with recent outset of acute neurological deficits of ischaemic origin were studied. Twenty-two sex-matched subjects aged 35-76 yr (mean $49.7 \pm 12.66)$ were taken as controls.

Beside clinical assessment, all the patients underwent standard noninvasive procedures, including EEG, Doppler sonography and serial CT scans. According to the severity and evolution of the clinical symptoms, patients were subdivided into those who had reversible ischaemic attacks (10 cases) and those with completed strokes (15 cases), without significant differences in age distribution between the two groups $(55.2 \pm 13.65$ and $59.46 \pm 10.93$ yr respectively).

The main population characteristics are reported in table 1. The CT findings refer to the examination performed within the week preceding or following the CSF sampling. Ischaemic oedema surrounding the focal lesions was present in $2 / 3$ reversible ischaemic attack cases ( 1 carotid; 1 vertebral) and in 4/13 stoke cases ( 3 carotid; 1 vertebral). CT pictures of diffuse white matter low attenuation were observed in two stroke patients (one without CT focal lesions). One or more previous transient ischaemic episodes had occurred in $9 / 10$ reversible ischaemic attack cases and in 10/15 stroke cases, with an interval of at least 3 months from the episode considered for the present investigation. Arterial hypertension and signs and symptoms of systemic atherosclerosis were present in 6 and 8/10 reversible ischaemic attacks and in 6 and $12 / 15$ stroke patients. A prodromal or concomitant "migraine-like" headache" associated with the ischaemic event we considered, was reported in six reversible ischaemic attacks and in three major events.

CSF and plamsa samples were taken at time intervals ranging from $48 \mathrm{~h}$ to 60 days from the acute event. In particular, $5 / 10$ reversible ischaemic attack and $6 / 15$ stroke cases were studied within the 2 nd week. All reversible ischaemic attack patients had a negative neurological examination at the time of sampling and had been on a standard hospital schedule for a nondisabled patient (meals at 7.00-12.00-18.00; sleep from 22.00 to 6.00). At the time of sampling $7 / 15$ stroke cases were severely disabled score 8 according to Patten et al, ${ }^{12}$ while the remaining cases were less severely disabled (score 4-7); those cases tested after the 2 nd week from symptoms onset were following a standard rehabilitation programme.

No patient had a previous history of psychiatric or endocrine disease, or had received centrally acting medications and/or dexamethasone during the week preceding the investigation. Among hypertensive patients only those $\bar{C}$ sufficiently controlled with diuretics took part in the study. At the time of observation none had depression (score of $\overline{\bar{S}}$ less than 20 on the Hamilton Rating Scale, ${ }^{13}$ nor mental deterioration (Mini Mental State more than 22)..$^{14}$

Control cases were selected among patients in whom $\infty$ neurological lesions had been suspected at entry, and who $\overrightarrow{0}$ had undergone a set of clinical and instrumental investigations with negative final results. Cases were excluded if $\vec{\omega}$ there was a history of major psychiatric disorder, alcohol $\$$ or drug abuse, signs and symptoms of cerebral coronary and/or peripheral atherosclerosis, arterial hypertension.

\section{Sampling procedures and assays}

CSF samples were obtained in all the patients and controbs by lumbar puncture at $9 \mathrm{am}$, after overnight fasting and $24 \mathrm{~h}$ bed rest. One $\mathrm{ml}$ aliquots were immediately freeze을 dried and stored under nitrogen. The integrity of the blood-brain barrier was evaluated in all the patients ẩ controls, according to Schliep and Felgenhauer ${ }^{1516}$ by measuring the CSF-plasma albumin gradient.

Heparinised blood samples $(500 \mathrm{kIU} / \mathrm{ml}$ aprotinim added) were taken before CSF collection, after 30 minuti saline infusion. Plasma obtained by centrifugation was stored at $-20^{\circ} \mathrm{C}$. $\beta$-EP and $\beta$-LPH radioimmunoassays were performed after silicic acid plasma extraction $(3 \mathrm{ml})$ and gel-chromatography of plasma extracts (or CSF reconstituted sample). According to elution profiles of cold $\bar{\partial}$ $\beta$-EP and $\beta$-LPH, two $16 \mathrm{ml}$ fractions discarding $6 \mathrm{ml}$ in 气 between were collected from a Sephadex column $(1.5 \times \mathbb{\Phi}$ $45 \mathrm{~cm}$ ), eluted with $0.1 \mathrm{M}$ acetic acid, $0.01 \%$ bovine serum albumin. Fractions, containing $\beta$-LPH and $\beta$-EP respectively, were freeze-dried, redissolved in $0.4 \mathrm{ml}$ phosphate buffer $0.05 \mathrm{M}, \mathrm{pH} 7.4$, and submitted to specific radioimmunoassays. The percent recovery of CSF samples was? $88.4 \pm 11.1 \%$ and $89.7 \pm 9.9 \%$ for $\beta$-LPH and $\beta$-EP, respectively, recovery of plasma samples was $70 \cdot 1 \pm 7.4 \%$ and $66.4 \pm 8.4 \%$. Synthetic $\beta$-EP was obtained from Organon (Oss, Holland), purified $\beta$-LPH and both anti $\mathrm{N}$-terminal and $\mathrm{C}$-terminal $\boldsymbol{\beta}$-LPH sera were generously supplied by Prof $\mathrm{CH}$ Li (San Francisco, CA, USA). Sen- O sitivity of both radioimmunoassays was $1.1 \mathrm{fmol} /$ tube. Details are reported elsewhere. ${ }^{17} 18$

ACTH was measured by radioimmunoassays on phosphate buffer, $\mathrm{pH} 7.4,0.04 \mathrm{M}$, redissolved CSF samples utilising both antiserum and reference hormone from NIADDK (Bethesda, MD, USA), and labelled molecule $\widetilde{\sim}$ from CIS (Saluggia, Italy). 
CSF and plasma levels of pro-opiomelanocortin-related peptides in reversible ischaemic attacks and strokes 19
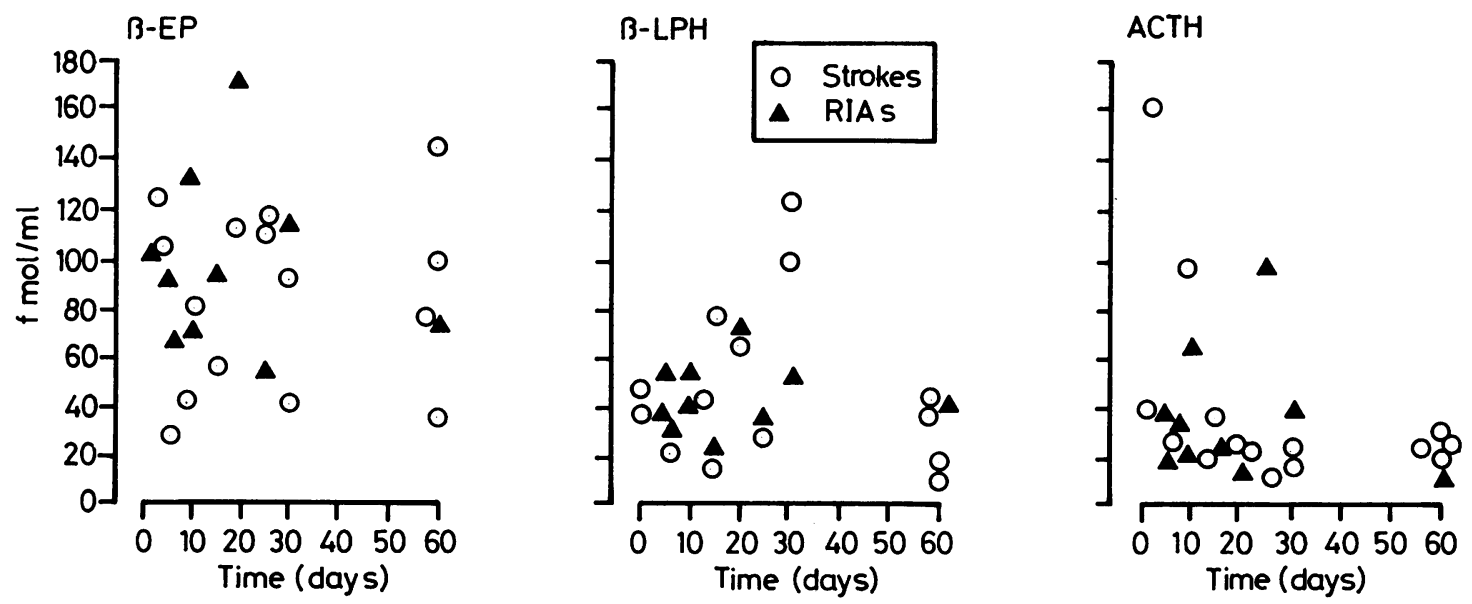

Fig $1 \beta-E P, \beta-L P H$ and ACTH CSF levels (single values) plotted against the time lapse between sampling and the acute event.

B-EP

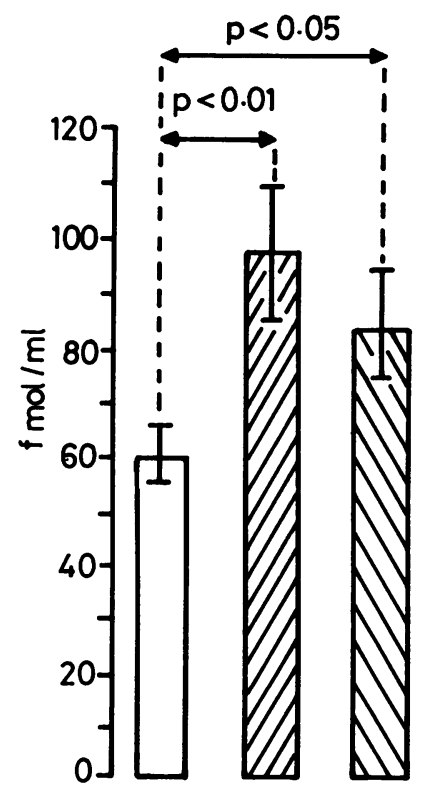

B-LPH

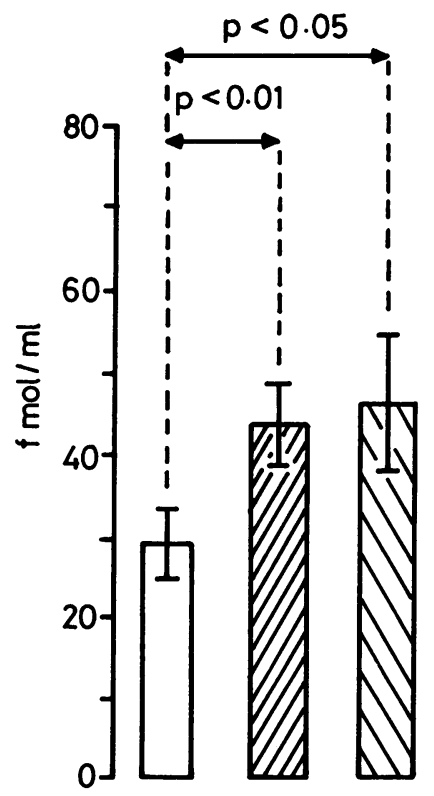

$\mathrm{ACTH}$
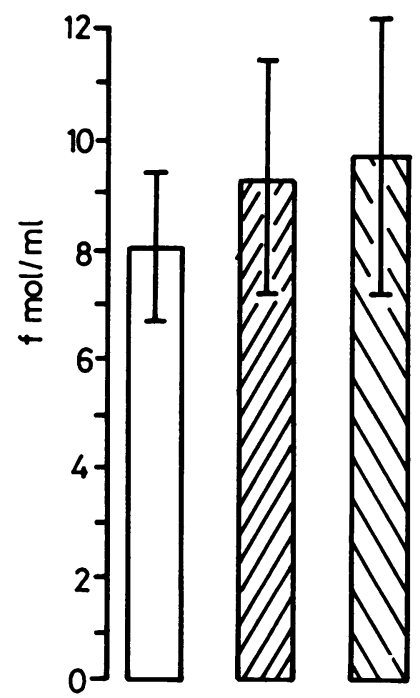

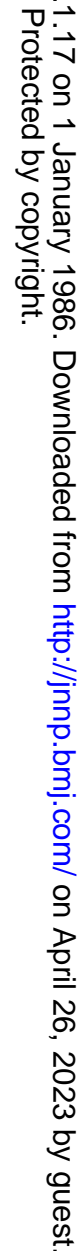

Fig $2 \beta-E P, \beta-L P H$ and ACTH levels $(M \pm S E)$ in the CSF of RIAs (10 cases), strokes (15 cases) and controls (22 cases). 
Table $2 \beta-E P, \beta-L P H$ and ACTH plasma concentrations $(M \pm S E)$ in ischaemic patients and controls

\begin{tabular}{|c|c|c|c|c|}
\hline & \multicolumn{3}{|l|}{ Patients } & \multirow{2}{*}{$\begin{array}{l}\text { Controls } \\
(22 \text { cases })\end{array}$} \\
\hline & Whole group ( 25 cases) & RIAs (10 cases) & Strokes (15 cases) & \\
\hline $\begin{array}{l}\beta \text {-EP } \\
\beta \text {-LPH } \\
\text { ACTH }\end{array}$ & $\begin{array}{r}9.2 \pm 1 \cdot 2 \\
6.9 \pm 0.7 \\
13 \cdot 1 \pm 0.9\end{array}$ & $\begin{array}{r}9 \cdot 7 \pm 2 \cdot 3 \\
7 \cdot 3 \pm 0 \cdot 2 \\
11 \cdot 0 \pm 2 \cdot 0\end{array}$ & $\begin{array}{r}8.7 \pm 3.4 \\
6.8 \pm 1.0 \\
14.7 \pm 0.8\end{array}$ & $\begin{array}{l}6 \cdot 9 \pm 0.6 \\
6 \cdot 6 \pm 0 \cdot 3 \\
14 \pm 2 \cdot 8\end{array}$ \\
\hline
\end{tabular}

\section{Results}

$\beta$-EP and $\beta$-LPH CSF levels of all ischaemic patients $(89.3 \pm 7 \cdot 1 ; 4.5 \cdot 1 \pm 5 \cdot 2 \mathrm{M} \pm \mathrm{SE})$ were significantly higher $(\mathrm{p}<0.01)$ than those of the control population $(65 \cdot 4 \pm 9 \cdot 0 ; 27 \cdot 3 \pm 2 \cdot 7)$. The difference was maintained even when the patients were subdivided into the two clinical subgroups, since, as shown in fig $1, \beta$-EP and $\beta$-LPH CSF levels of reversible ischaemic attack $(97.4 \pm 11 \cdot 1 ; 43.2 \pm$ $4.5)$ and stroke $(84.3 \pm 9.4 ; 46.4 \pm 8 \cdot 2)$ patients remained significantly higher $(p<0.01 ; p<0.05$, respectively) than those of the controls. On the contrary, ACTH CSF values did not show differences either between patients $(9.5 \pm 1.7)$ and controls $(8.0 \pm 1.4)$, or between the clinical subgroups of ischaemic episodes (reversible ischaemic attack, 9.2 $\pm 2 \cdot 1$, stroke, $9 \cdot 7 \pm 2 \cdot 6$ )

When the opioid and ACTH levels were plotted against the time intervals between sampling and symptoms onset (fig 2 ), no correlations. were found $(\beta$-EP $\mathrm{r}=0.003 ; \beta$-LPH $\mathrm{r}=-0.01 ;$ ACTH $\mathrm{r}=$ $-0 \cdot 1)$. The same was true when considering the blood brain barrier damage, a variable that, in the population as a whole, seemed not to influence the distribution of the elevated opioid levels (maintained: $\beta$-EP $92.6 \pm 7 \cdot 5 ; \beta$-LPH 49.9 \pm 6.4 ; ACTH $6 \cdot 0 \pm 0.3$; damaged: $\beta$-EP $86 \pm 7 \cdot 1 ; \beta$-LPH $39.9 \pm$ 3.4; ACTH 13.3 $\pm 2 \cdot 2$ ).

The $\beta$-EP CSF values of the patients were correlated $(\mathrm{p}<0.05)$ with the presence $(103.8 \pm 7.5)$ or absence (78.3 $\pm 5 \cdot 2)$ of $C T$ focal ischaemic lesions. No correlation, however, was observable when $\beta$-LPH and ACTH levels were considered.

Considering the territory involved, previous transient ischaemic events, arterial hypertension and the signs and symptoms of systemic atherosclerosis, no statistical significances were found. In particular, no difference appeared when comparing the mean values of patients with prodromal or concomitant headache associated with the ischaemic event $(\beta-E P$ $84 \pm 17 \cdot 0 ; \beta$-LPH $53 \cdot 1 \pm 10 \cdot 1 ;$ ACTH $7 \cdot 5 \pm 1 \cdot 6$ ) with those without $(\beta$-EP $56 \cdot 1 \pm 12 \cdot 8 ; \beta$-LPH $46 \cdot 1$ $\pm 6 \cdot 1$; ACTH $5 \cdot 6 \pm 0 \cdot 4)$.

Plasma concentrations of the three peptides are reported in table 2 ; there was no difference between patients and controls, even when the two clinical subgroups of ischaemic episodes were considered.

\section{Discussion}

These data demonstrate that focal cerebral ischaemia is associated with increased $\beta$-EP and $\beta$-LPH CSF levels, which appear to be independent of both the clinical reversibility of the cerebral damage and the time lapse between sampling and the acute event. Moreover, the maintained integrity of the blood brain barrier does not interfere with the opioid levels either in reversible ischaemic attack and in stroke subgroups.

These findings agree and enlarge the preliminary observations by Hosobuchi's group, ' demonstrating an involvement of central opioid substances in the phenomena related to brain ischaemia, even if there? are conflicting data in humans about naloxone reversible ischaemia. ${ }^{19}$ Moreover, it is of interes that ACTH CSF content remains unaffected; this could suggest that the raised $\beta$-EP and $\beta$-LPH con? centrations are a selective consequence of the ischaemic injury and further support the concept of an independent central secretion of proopiomelanocortin-related peptides. ${ }^{18}$

Several hypotheses could be advanced in order to explain the $\beta$-EP increase after focal brain ischaemia. The opioid release could be stimulated by general hypoxia, acidosis and hypercapnia, as can occur in the peripheral circulation..$^{20}$ Otherwise, bearing in mind the positive action of 5-HT on pituitary and hypothalamic ${ }^{21} \beta$-EP content, the increase of both opioids could be a phenomenon secondary to the augmentation of 5- $\mathrm{HT}$ release in the CSF after cerebral ischaemia. ${ }^{22}$ Lastly, the increased opioid levels in CSF could be related to diaschisis, a neurogenic phenomenon that is thought to influence cerebral blood flow and metabolism in areas far from the focal lesion..22 Discrepancies between the severity of the clinical symptoms and the CT findings are commonly found in cerebrovascular ischaemic disorders, ${ }^{23}$ even when the patients with positive CT findings for focal ischaemia showed the highest $\beta$-EP levels.

As far as the peripheral plasma concentrations are 
concerned, neither ACTH nor $\beta$-EP, nor $\beta$-LPH plasma levels of patients differ from the control group. These results are in agreement with observations by Fallis et al, ${ }^{24}$ and further confirm that CSF and plasma content of pro-opiomelanocortinrelated peptides are differently controlled, originate from different sources and are not linked by any relationship. ${ }^{18}$

In conclusion, focal cerebral ischaemia, either reversible or permanent, is accompanied by high CSF $\beta$-EP and $\beta$-LPH levels, independently of the clinical picture. The occurrence of a demonstrable CT focal lesion is the factor which directly correlates with the maximal rise of $\beta$-EP, regardless of possible alterations in the blood brain barrier.

\section{References}

' O'Donohue TL, Dorsa DM. The opiomelanotropinergic neuronal and endocrine system. Peptides 1982;3:353-95.

${ }^{2}$ Levy R, Feustel P, Severinghans J, Hosobuchi Y. Effect of naxolone on neurological deficit and cortical blood flow during focal cerebral ischemia in cats. Life Sci 1982;31:2205-8.

${ }^{3}$ Faden AJ, Hallenbeck JM, Brown CQ. Treatment of experimental stroke: comparison of naxolone and thyrotropin releasing hormone. Neurology (NY) 1982;32:1083-7.

${ }^{4}$ Baskin DS, Kieck CF, Hosobuchi Y. Naloxone reversal of ischemic neurological deficits in baboons is not mediated by systemic effects. Life Sci 1982;31:2201-4.

${ }^{5}$ Meyer JS. Disorder neurotransmitter functions: demonstration by measurement of norepinephrine and 5-hydroxytryptamine in CSF of patients with recent cerebral infarction. Brain 1974;97:655-60.

- Mrsulja BB, Mrsulja BJ, Spate M, Klatzo J. Brain serotonin after experimental vascular occlusion. Neurology (Minneap) 1976;26:785-90.

${ }^{7}$ Baskin DS, Hosobuchi Y. Naxolone reversal of ischemic neurological deficits in man. Lancet 1982;8:272-5.

${ }^{8}$ Hosobuchi Y, Baskin DS, Woo SK. Reversal of induced ischemic neurological deficits in gerbils by the opiate antagonist naxolone. Science 1982;215:69-71.

${ }^{9}$ Faden AJ. Neuropeptides and stroke: current status and potential application. Stroke 1983;14:169-72.

${ }^{10}$ Loeb C. Clinical evaluation of patients with transient ischemic attacks. In; Goldstein M, Bolis L, Fieschi C, Gorini S, Millikan $\mathrm{CH}$, eds. Cerebrovascular Disor- ders and Stroke. New York: Raven Press 1979:141-8.

1 Nappi G, Bono G. Headache and transient cerebral ischemia. In: Critchley $M$, Friedman $A$, Gorini $S$, Sicuteri F, eds. Headache-Physiopathological and Clinical Concepts. New York: Raven Press 1982: 41-50.

12 Patten BM, Mendell J, Bruun B, Curtin W, Carter S. Double-blind study of the effects of dexamethasone on acute stroke. Neurology (Minneap) 1972;22:37783.

${ }^{13}$ Hamilton M. A rating scale of depression. $J$ Neurol Neurosurg Psychiatry 1960;23:56-62.

${ }^{14}$ Folstein MF, Folstein SE, McHugh PR. Mini-Mental State. J Psych Res 1975;12:189-98.

is Schliep G, Felgenhauer K. Serum CSF protein gradients, the blood CSF barrier and the local immuno response. J Neurol 1978;218:77-96.

${ }^{16}$ Savoldi F, Mazzella GL, Facchinetti F, Nappi G, Petraglia F, Sinforiani E, Parrini D, Genazzani AR. Betaendorphin, beta-lipotropin and adrenocorticotropic hormone levels in cerebrospinal fluid, and brain damage in chronic alcoholics. Eur Neurol 1983;22:26571.

${ }^{17}$ Genazzani AR, Nappi G, Facchinetti F, Mazzella GL, Parrini D, Sinforiani E, Petraglia F, Savoldi F. Central deficiency of $\beta$-endorphin in alcohol addicts. $J$ Clin Endocrinol Metab 1982;55:583-6.

${ }^{18}$ Faccinetti F, Petraglia F, Nappi G, Martignoni E, Antoni G, Parrini D, Genazzani AR. Different patterns of central and peripheral $\beta$-EP, $\beta$-LPH and ACTH throughout life. Peptides $1983 ; 4: 469-74$.

${ }^{19}$ Cutler JR, Bredsen DE, Edwards R, Simon RP. Failure of naxolone to reverse vascular neurologic deficits. Neurology (NY) 1983;33:1517-8.

${ }^{20}$ Wardlaw SL, Stark RI, Bacsi L, Franz AG. Plasma $\beta$-endorphin and $\beta$-lipotropin in the human fetus after delivery: correlation with arterial $\mathrm{pH}$ and $\mathrm{PCO}_{2} . \mathrm{J}$ Clin Endocrinol Metab 1979;49:888-92.

${ }^{21}$ Petraglia F, Penalva A, Genazzani AR, Müller EE. Stimulation of $\beta$-endorphin and $\beta$-lipotropin release from the anterior, but not the neurointermediate pituitary lobe in the rat after acute adminstration of serotonin acting drugs. Life Sci 1982;31:2809-17.

${ }^{22}$ Welch KMA, Gaudet R, Wang TPF, Chabi E. Transient cerebral ischemia and brain serotonin: relevance to migrain. Headache 1977; 17:145-7.

${ }^{23}$ Müller HR. The place of computerized tomography and carotid Doppler sonography in $\mathrm{CV}$ episodes. In: Goldstein M, Bolis L, Fieschi C, Gorini S, Millikan $\mathrm{CH}$, eds. Cerebrovascular Disorders and Stroke. New York: Raven Press 1979:181-98.

${ }^{24}$ Fallis R, Fisher M, Lobo R. A double-blind trial of naxolone in acute stroke. Stroke 1983;14:124. 